JOHNSON, D. A. \& FREEMAN, H. (1972) Longacting tranquillizers. The Practitioner, 208, 395-400.

columns
— \& FREEMAN, H. (1973) Drug defaulting by patients on long-acting phenothiazines. Psychological Medicine, 3, 115-119.

WOOFF, K., FREEMAN, H. L. \& FRYERS,T. (1983) Psychiatric service use in Salford. A comparison of point-prevalence ratios 1968 and 1978. British Journal of Psychiatry, 142, 588-597.

Hugh L. Freeman Professor, 21 Montagu Square London W1H 2LF

\section{Changing Minds campaign}

Sir: Professor Crisp (Psychiatric Bulletin, November 2001, 25, 444-446) gave an update on the Changing Minds campaign, and concluded by urging all areas of the College to participate actively in this campaign. As someone who has helped to run one of the Stigma Alert educational roadshows aimed at general practitioners (GPs), I would like to add further encouragement to any College members thinking of offering their support.

The difficulty in finding someone to speak at the event on behalf of service users gave strong evidence as to the continuing impact of stigma on the lives of our patients. The speaker I eventually found spoke eloquently about the experience of rejection by her former employers, and the fact that some mental health professionals are still wary of accepting her in her recovered role as a support worker because they remember the time when she was an in-patient.

It is hard to say if the meeting changed the minds of the handful of GPs who attended. It certainly was a very useful bridge-building occasion, bringing together local health professionals and patients, and carers groups. Moreover, I can confirm that participating in the campaign has changed my mind. My awareness of stigmatising attitudes has been so heightened that I find myself moved to respond actively where I see psychiatry maligned, and possibly more invidiously, ignored.

Another round of these meetings is planned for the spring throughout the UK, and Liz Cowan at the campaign office (Royal College of Psychiatrists, 17 Belgrave Square, London SW1X 8PG) would be pleased to hear from interested College Members.

Liz Hare Specialist Registrar, Community Rehabilitation Service, Rehabilitation Service, West Brig Tweed Road, GalashielsTD1 3EB

\section{Nurses' uniforms}

Sir: In July 2001 the psychiatric nursing staff in the mental health unit in Leigh Infirmary, Leigh, Lancashire, balloted to go back to wearing their nursing uniforms in all the in-patient psychiatric wards, including the psychiatric intensive care unit, acute male and female wards, and rehabilitation wards. Within the previous 3 years there were multiple requests independent of each other to return to wearing uniforms, coming mainly from relatives, service users and in-patient staff. Reasons given for the request were in relation to clearer identification of staff, better boundaries with patients and a more professional rapport, which would lead to a better established alliance.

The decision was taken following long discussions with consultants, medical and nursing staff, and service management, and a ballot of the nurses, which reflected unanimous interest in wearing nursing uniforms.

Five months later all involved seem to be happy with the decision and wish to continue to wear uniforms. Patients, relatives and staff express satisfaction with the process. There has been a great reduction in aggression, violence and the number of untoward incidents on the wards. In-patients have been more collaborative and understanding of the alliance with the professionals.

Since this is an unusual practice in mental health services today, I wish to share this experience with colleagues.

Dora Kohen Professor of Psychiatry, Lancashir Postgraduate School of Medicine and Health, Department of Psychiatry, Leigh Infirmary, Leigh, Lancaster WN7 1HS

\section{Driving and substance misuse}

Sir: Further to the paper by Bradbeer et al (Psychiatric Bulletin, July 2001, 25 252-254) and the letter of Kirk et al (Psychiatric Bulletin, November 2001, 25, 452), please see Box 1 below, which is available at our in-patient alcohol treat ment facilities. The leaflets are taken away and at least sometimes read, judging by the questions that patients ask us. We agree with the difficulties noted by Kirk et al in bringing up the issue in the clinical interview in some instances where patients are ambivalent about their attendance at the clinic.

D. Chick Consultant Psychiatrist E. B. Ritson Consultant Psychiatrist, Out-patient Department, Lothian Primary Care NHS Trust, 35 Morningside Park, Edinburgh EH10 5HD

\section{Box 1. Alcohol, driving and the law (Chick \& Ritson correspondence)}

Most people know that it is unwise to drink then drive, and against the law to drive with more than $80 \mathrm{mg}$ per cent of alcohol in the blood. A breath test or a blood test can be used by the police. You can also have this level first thing in the morning after drinking heavily the night before. Many people who have alcohol problems are careful to avoid driving when they have been drinking. If you are addicted to alcohol you find it very difficult to stop drinking, and in these circumstances you must not drive.

Notifying the Driver and Vehicle Licensing Agency (DVLA)

According to the Road Traffic Act, there are certain medical conditions where an individual is required by law to notify the DVLA. Most people know that epilepsy and diabetes are included. Few people know that dependence on alcohol or misuse of alcohol are also medical conditions requiring notification. This is also listed in a European Union Directive to which the UK is a signatory.

What will happen if I notify the DVLA?

If you notify the DVLA that you have an alcohol problem, the Drivers' Medical Group may ask for a report from your doctor. You may well be allowed to continue to hold your licence, but a further report may be needed in future, or they may withhold your licence until a medical report gives evidence that you are recovering from your alcohol problems. The medical report might involve your doctor taking a blood sample.

What about my insurance?

Insurance companies may vary in their approach to this and we can give no fixed guidance. Voluntarily notifying of the DVLA of your alcohol problem would be very unlikely to affect the cost of your car insurance. On the other hand, in theory, claims by a driver with an alcohol problem who had not declared his / her condition to the DVLA might not be met by the insurer. To date, we have not heard of this happening.

Recommendations

People with alcohol problems who are drivers should write to DVLA Medical Group at D6/03 Longview Road, Swansea SA99 1TU to ask for advice. It is a very busy office and they do not recommend telephoning for advice. 